\title{
BMJ Open Evaluating the accessibility and utility of HIV-related point-of-care diagnostics for maternal health in rural South Africa: a study protocol
}

\author{
T P Mashamba-Thompson, ${ }^{1}$ P K Drain, ${ }^{2,3,4}$ B Sartorius ${ }^{1}$
}

To cite: MashambaThompson TP, Drain PK, Sartorius B. Evaluating the accessibility and utility of HIV-related point-of-care diagnostics for maternal health in rural South Africa: a study protocol. BMJ Open 2016;6:e011155

doi:10.1136/bmjopen-2016011155

- Prepublication history and additional material is available. To view please visit the journal (http://dx.doi.org/ 10.1136/bmjopen-2016011155).

Received 14 January 2016 Revised 1 April 2016 Accepted 26 April 2016

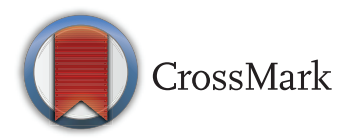

For numbered affiliations see end of article.

\section{Correspondence to} T P Mashamba-Thompson; Mashamba-Thompson@ukzn. ac.za

\begin{abstract}
Introduction: Poor healthcare access is a major barrier to receiving antenatal care and a cause of high maternal mortality in South Africa (SA). 'Point-of-care' (POC) diagnostics is a powerful emerging healthcare approach to improve healthcare access. This study focuses on evaluating the accessibility and utility of POC diagnostics for maternal health in rural SA primary healthcare (PHC) clinics in order to generate a model framework of implementation of POC diagnostics in rural South African clinics.
\end{abstract}

Method and analyses: We will use several research methods, including a systematic review, quasi-experiments, survey, key informant interviews and audits. We will conduct a systematic review and experimental study to determine the impact of POC diagnostics on maternal health. We will perform a cross-sectional case study of 100 randomly selected rural primary healthcare clinics in KwaZulu-Natal to measure the context and patterns of POC diagnostics access and usage by maternal health providers and patients. We will conduct interviews with relevant key stakeholders to determine the reasons for POC deficiencies regarding accessibility and utility of HIV-related POC diagnostics for maternal health. We will also conduct a vertical audit to investigate all the quality aspects of POC diagnostic services including diagnostic accuracy in a select number of clinics. On the basis of information gathered, we will propose a model framework for improved implementation of POC diagnostics in rural South African public healthcare clinics. Statistical (Stata-13) and thematic (NVIVO) data analysis will be used in this study.

Ethics and dissemination: The study protocol was approved by the Ethics Committee of the University of KwaZulu-Natal (BE 484/14) and the KwaZulu-Natal Department of Health based on the Helsinki Declaration (HRKM 40/15). Findings of this study will be disseminated electronically and in print. They will be presented to conferences related to HIV/AIDS, diagnostics, maternal health and strengthening of health systems.

\section{INTRODUCTION}

South Africa (SA) has $\sim 6$ million HIV-infected people, most of them women with $27 \%$ of pregnant women living with HIV. $^{1}$ Of this, the highest infection rate at

\section{Strengths and limitations of this study}

- This study will include relevant key stakeholders of point-of-care (POC) diagnostics in the study setting.

- Evaluation will reveal barriers and challenges that need to be addressed before the adoption of new POC diagnostics or scaling up the current POC diagnostics services in the study setting.

- To ensure reliability of results, the evaluation of POC test performance will only include PHC clinics that are within close proximity to the testing laboratory.

$10 \%$ higher than the national average as well as HIV prevalence and maternal death rates are seen in the KwaZulu-Natal (KZN) province. ${ }^{1}$ The South African National Strategic Plan (NSP) for HIV, tuberculosis and sexually transmitted infections 2012-2016 contains important recommendations linked to maternal health and highlights the importance of innovations such as point-of-care (POC) diagnostics for improvement of patient outcomes. ${ }^{2}$ Unicef reports the need to prioritise the improvement of quality of SA health services at primary care level, ensuring timely referral of patients to higher levels of the health system when necessary. ${ }^{2}$ There remains a lack of uniformity in SA primary health service distribution resulting in failure to meet the unmet needs of patients in resource-limited settings. ${ }^{3}$ Research studies have demonstrated the implications of poor access to healthcare services in SA rural communities $^{45}$ and the usefulness of POC diagnostics for the improvement of healthcare access in rural and resource-limited communities in the developing world. ${ }^{67}$

A major advantage of POC diagnostics over standard laboratory testing is the ability to provide rapid results, permitting timely initiation of suitable therapy as well as facilitating 
linkages to care and referrals. ${ }^{8}$ POC diagnostics has the potential to improve healthcare services by enabling delivery of pathology testing in settings that have limited access to laboratory infrastructure. ${ }^{8}$ For these reasons, these diagnostics have the potential to play a major role in revolutionising the diagnosis, initiation and monitoring of treatment of major global diseases. The clinical impact of POC diagnostics has been shown in a variety of infectious diseases, including HIV/AIDS. ${ }^{8}$ Consequently, WHO called for new clinical diagnostics methods that are designed to function in settings with limited access to laboratory services ${ }^{9}$ leading to an increase in marketing, manufacturing and development of POC diagnostic instruments and reagents for clinical use. ${ }^{10}$

The use of POC diagnostics could prevent more than 1.2 million deaths from HIV/AIDS, its co-infections and malaria. ${ }^{11}$ However, previous research has demonstrated that the availability of health technologies in these settings does not always guarantee patient-centred outcomes. ${ }^{12}$ Implementation of diagnostic POC tests should be evaluated within a given context to ensure the utility of these novel technologies developed in high income countries for use in low income countries. ${ }^{13}{ }^{14}$ Evaluations are needed in developing, low-resource settings where pregnant and postnatal HIV-positive mothers have poor access to quality healthcare facilities and clinical laboratories. ${ }^{15}$

Gaining insight into these barriers is useful for informing POC diagnostic developers, policymakers, clinicians and users to ensure the usefulness of POC diagnostics in reducing HIV-related maternal mortality in rural resource-limited settings. The overarching aim of this study is to evaluate the accessibility, availability and utility of POC diagnostic services for rural primary healthcare clinics in SA in order to develop an ideal model framework and recommendations for improved implementation of POC diagnostics in these settings. The following objectives will be outlined in order to address the aim of the study: first, to investigate the typology, supply chain POC diagnostics in rural PHC clinics in SA; second, to investigate the deficiencies and their causes for POC diagnostics in rural PHC clinics in SA; third, to investigate the quality management systems emplaced to ensure reliability of the HIV-related POC diagnostics for maternal health in their current setting; fourth, to determine the impact of HIV-related POC diagnostics on maternal mortality using an interrupted time series study; fifth, to evaluate whether introduction POC diagnostics into algorithms for diagnosing maternal patients, improves maternal health for HIV-infected women using a systematic review and finally to develop a model framework and recommendations for improved implementation of POC diagnostics on SA rural PHCs.

\section{METHODS}

A summary of the methodology used by this multiphase/component study can be found in table 1. In this study, we will use several research methods to determine the impact of POC diagnostics on maternal health in rural KZN. We define rural as sparsely populated areas in which people farm or depend on natural resources, including the villages and small towns that are dispersed through these areas. In addition, they include the large settlements in the former homelands, created by the apartheid removals, which depend, for their survival, on migratory labour and remittances.

\section{Overall design}

The programme evaluation theory is a promising approach to explain how a programme produces the desired effects. ${ }^{17-19}$ This theory argues that effective implementation of a programme requires gathering of evidence from relevant stakeholders. ${ }^{17}$ 20 The programme evaluation theory involves three distinctive approaches: postpositivism, interpretivism and critical normative science paradigm. ${ }^{21}$ Adopting the postpostivism paradigm will enable us to rationally deduce research experience and interpret into concepts and knowledge. $^{22}$ The interpretivism paradigm will enable us to contextualise subjective realities of study participants in terms of their experiences of POC diagnostics' challenges and barriers and enable us to attach this to meaning and qualitative evidence. ${ }^{23}$ The critical normative science paradigm will enable a critical analysis of POC diagnostic services in order to determine its merit. Combining the programme evaluation theory paradigms, we develop a theoretical framework to guide this study (figure 1). We will use data triangulation to increase confidence and diversity regarding the research data. ${ }^{1624}$ Data for this study will be collected from seven sources: surveys, interviews, record review, District Health Information Software (DHIS) routine data, peerreviewed literature and audits.

\section{Research team and study settings}

The evaluation study will be carried out in KZN province, SA. KZN is located in the southeast of the country on the coast of the Indian Ocean, shares borders with three other provinces and the countries of Mozambique, Swaziland and Lesotho. KZN is the largest province in SA consisting of 11 districts and 52 municipalities and consists of a mix of urban, semiurban and rural areas. The province has a total population of 10694400 , of which $86.8 \%$ are black Africans and Zulu speakers. ${ }^{25}$ A representative subset of maternal health primary healthcare clinics in rural KZN will be sampled for this study.

\section{Data sources, sampling variables and analyses}

The full data analysis plan for each objective/component can also be found in table 1 . In this study, various methods of data collection and interpretation will be used as an integrated form to carry out methodological triangulation of sources for collecting quantitative and qualitative samples. $^{22} 23$

Objective 1: To investigate the typology, supply chain POC diagnostics in rural PHC clinics in SA. 
Table 1 Summary of the methodology

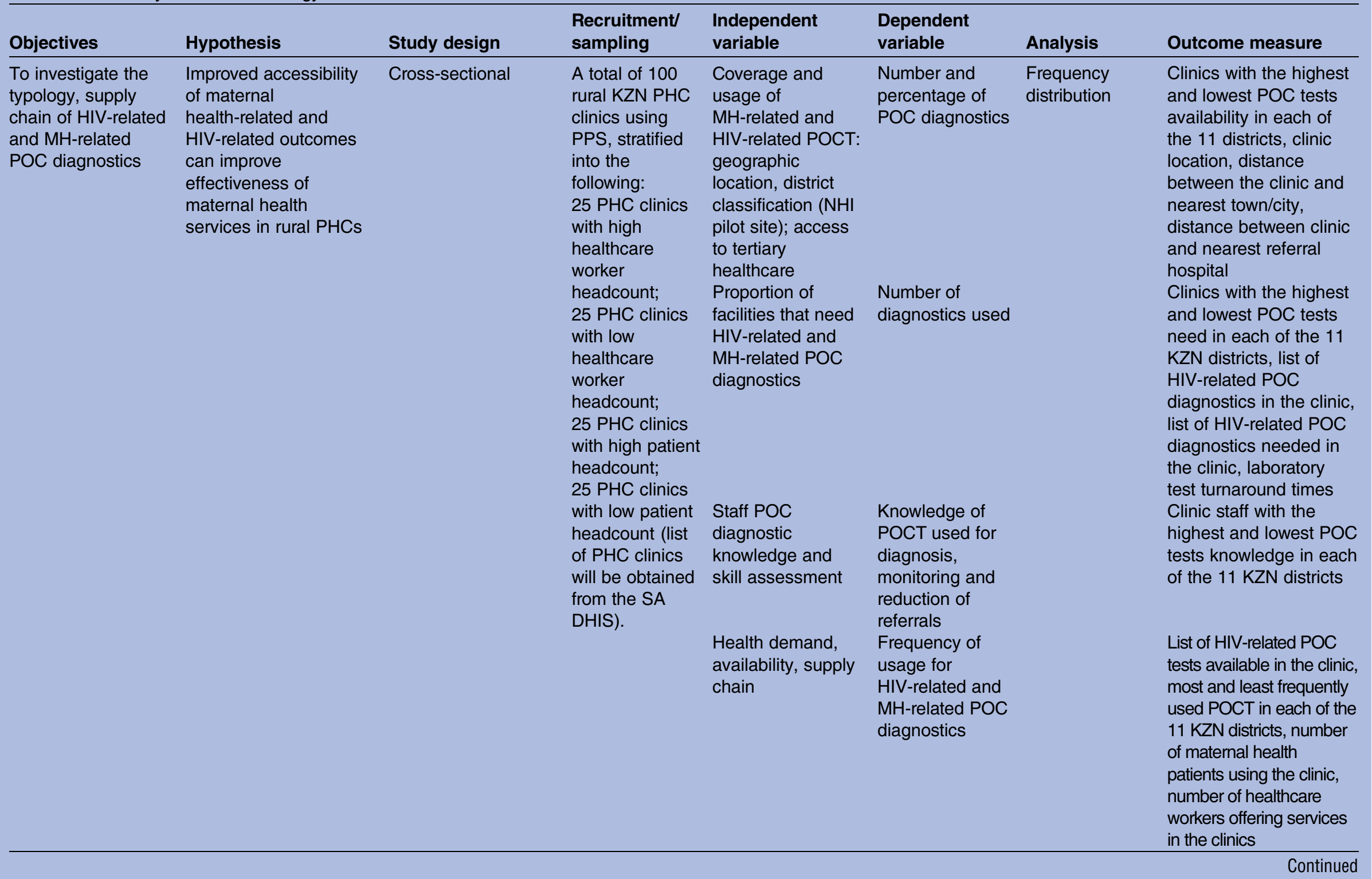




\begin{tabular}{|c|c|c|c|c|c|c|c|}
\hline Objectives & Hypothesis & Study design & $\begin{array}{l}\text { Recruitment/ } \\
\text { sampling }\end{array}$ & $\begin{array}{l}\text { Independent } \\
\text { variable }\end{array}$ & $\begin{array}{l}\text { Dependent } \\
\text { variable }\end{array}$ & Analysis & Outcome measure \\
\hline $\begin{array}{l}\text { To investigate } \\
\text { deficiencies and } \\
\text { their causes in } \\
\text { HIV-related and } \\
\text { maternal health } \\
\text { related POC } \\
\text { diagnostics }\end{array}$ & $\begin{array}{l}\text { Demonstrating the } \\
\text { causes linked to poor } \\
\text { accessibility of maternal } \\
\text { health-related and } \\
\text { HIV-related outcomes } \\
\text { can help inform and } \\
\text { guide implementers } \\
\text { during scaling up of } \\
\text { current POC services } \\
\text { and adoption of new } \\
\text { POC services }\end{array}$ & In-depth interviews & $\begin{array}{l}\text { Healthcare } \\
\text { workers from } \\
\text { PHCs with low } \\
\text { availability and } \\
\text { usage of POC } \\
\text { diagnostics; } 11 \\
\text { public health } \\
\text { officials from } \\
\text { each (1 from } \\
\text { each district) }\end{array}$ & $\begin{array}{l}\text { Management; } \\
\text { human resources; } \\
\text { infrastructure; staff } \\
\text { knowledge, skill } \\
\text { and attitude; } \\
\text { believes; } \\
\text { stakeholder } \\
\text { perception }\end{array}$ & $\begin{array}{l}\text { Level of } \\
\text { accessibility, } \\
\text { availability and } \\
\text { usage and of } \\
\text { HIV and MH } \\
\text { POCT for } \\
\text { maternal health } \\
\text { services }\end{array}$ & $\begin{array}{l}\text { Thematic } \\
\text { analysis }\end{array}$ & NA \\
\hline \multirow[t]{5}{*}{$\begin{array}{l}\text { To investigate the } \\
\text { QMS emplaced to } \\
\text { ensure reliability of } \\
\text { the HIV-related and } \\
\text { MH-related POC } \\
\text { diagnostics in their } \\
\text { current setting }\end{array}$} & $\begin{array}{l}\text { Providing evidence on } \\
\text { the reliability and } \\
\text { sustainability of the } \\
\text { QMS for PHC-based } \\
\text { POCT can provide } \\
\text { reassurance to }\end{array}$ & $\begin{array}{l}\text { Vertical assessment/ } \\
\text { audit against SANAS } \\
\text { ISO 15189:2012 and } \\
\text { ISO 22870:2006 }\end{array}$ & $\begin{array}{l}\text { Document } \\
\text { review from } \\
\text { PHCs with high } \\
\text { availability and } \\
\text { usage of POC } \\
\text { diagnostics. }\end{array}$ & $\begin{array}{l}\text { Infrastructure; } \\
\text { QMS; operational } \\
\text { time taken from } \\
\text { results reporting to } \\
\text { patient treatment } \\
\text { for routine cases }\end{array}$ & $\begin{array}{l}\text { Level of quality } \\
\text { of service } \\
\text { delivery }\end{array}$ & $\begin{array}{l}\text { Correlation } \\
\text { coefficient }\end{array}$ & $\begin{array}{l}\text { Overall compliance with } \\
\text { relevant ISO standards }\end{array}$ \\
\hline & $\begin{array}{l}\text { implementers during } \\
\text { scaling up of current }\end{array}$ & & Ease of use & User acceptability & & $\begin{array}{l}\text { Correlation } \\
\text { coefficient }\end{array}$ & $\begin{array}{l}\text { Overall compliance with } \\
\text { relevant ISO standards }\end{array}$ \\
\hline & $\begin{array}{l}\text { POC services and } \\
\text { adoption of new POC } \\
\text { services }\end{array}$ & & $\begin{array}{l}\text { Linkage to } \\
\text { healthcare }\end{array}$ & $\begin{array}{l}\text { Time from } \\
\text { diagnosis to } \\
\text { healthcare }\end{array}$ & $\begin{array}{l}\text { Diagnostics } \\
\text { turnaround times }\end{array}$ & $\begin{array}{l}\text { Correlation } \\
\text { coefficient }\end{array}$ & $\begin{array}{l}\text { Overall compliance with } \\
\text { relevant ISO standards }\end{array}$ \\
\hline & & Efficacy test & $\begin{array}{l}\text { Blood samples } \\
\text { from maternal } \\
\text { health patients } \\
\text { who are } \\
\text { receiving POC } \\
\text { diagnostic } \\
\text { services from } \\
\text { PHCs with high } \\
\text { quality of POC } \\
\text { diagnostics } \\
\text { service delivery. }\end{array}$ & $\begin{array}{l}\text { Stability of the test } \\
\text { under user } \\
\text { conditions }\end{array}$ & $\begin{array}{l}\text { Specificity; } \\
\text { sensitivity; } \\
\text { positive and } \\
\text { negative } \\
\text { likelihood ratios; } \\
\text { PPV and NPV }\end{array}$ & $\begin{array}{l}\text { 95\% Cls and } \\
\text { paired Z test to } \\
\text { compare Cls of } \\
\text { validation } \\
\text { indices } \\
\text { (sensitivity; } \\
\text { specificity; NPV } \\
\text { and PPV } \\
\text { א-statistic) } \\
\text { between POC } \\
\text { diagnostics } \\
\text { results and } \\
\text { laboratory } \\
\text { results }\end{array}$ & $\begin{array}{l}\text { Correlation between the } \\
\text { laboratory and POCT } \\
\text { results }\end{array}$ \\
\hline & & & $\begin{array}{l}\text { The sample } \\
\text { size at the } \\
\text { required } \\
\text { absolute }\end{array}$ & $\begin{array}{l}\text { Reliability of the } \\
\text { POCT results }\end{array}$ & $\begin{array}{l}\text { Accuracy of } \\
\text { results in } \\
\text { comparison with }\end{array}$ & $\begin{array}{l}\text { Correlation } \\
\text { coefficient }\end{array}$ & $\begin{array}{l}\text { Correlation between the } \\
\text { laboratory and POCT } \\
\text { results }\end{array}$ \\
\hline
\end{tabular}




\begin{tabular}{|c|c|c|c|c|c|c|c|}
\hline Objectives & Hypothesis & Study design & $\begin{array}{l}\text { Recruitment/ } \\
\text { sampling }\end{array}$ & $\begin{array}{l}\text { Independent } \\
\text { variable }\end{array}$ & $\begin{array}{l}\text { Dependent } \\
\text { variable }\end{array}$ & Analysis & Outcome measure \\
\hline & & & $\begin{array}{l}\text { precision level } \\
\text { for sensitivity } \\
\text { and specificity } \\
\text { will be } \\
\text { dependent on } \\
\text { survey, vertical } \\
\text { audit results } \\
\text { and clinic size. } \\
\text { It will can be } \\
\text { calculated by } \\
\text { Buderer's } \\
\text { formula. }^{16}\end{array}$ & & $\begin{array}{l}\text { gold standard } \\
\text { (ELISA) }\end{array}$ & & \\
\hline $\begin{array}{l}\text { To determine the } \\
\text { impact of } \\
\text { HIV-related and } \\
\text { MH-related POC } \\
\text { diagnostics on } \\
\text { maternal mortality } \\
\text { using } \\
\text { quasi-experiment }\end{array}$ & $\begin{array}{l}\text { Demonstrating the } \\
\text { impact of HIV-related } \\
\text { and MH-related POC } \\
\text { tests on maternal } \\
\text { mortality provides merit/ } \\
\text { worth for POC testing } \\
\text { scale up in KZN } \\
\text { maternal health clinics }\end{array}$ & $\begin{array}{l}\text { Quasi-experimental, } \\
\text { interrupted time } \\
\text { series }\end{array}$ & $\begin{array}{l}\text { DHIS data on } \\
\text { MMR data from } \\
\text { the PHC clinics } \\
\text { with high quality } \\
\text { of POC } \\
\text { diagnostics } \\
\text { service delivery. }\end{array}$ & $\begin{array}{l}\text { Time aggregation: } \\
\text { monthly level, } \\
\text { facility level; } \\
\text { facility-specific time } \\
\text { of implementation } \\
\text { of POC diagnostics } \\
\text { (syphilis) will be } \\
\text { used as a break } \\
\text { point of in } \\
\text { segmented } \\
\text { regression }\end{array}$ & $\begin{array}{l}\text { Change in } \\
\text { maternal } \\
\text { mortality rate }\end{array}$ & $\begin{array}{l}\text { Segmented } \\
\text { regression } \\
\text { modelling }\end{array}$ & $\begin{array}{l}\text { Reduction in maternal } \\
\text { mortality post-POCT } \\
\text { implementation. }\end{array}$ \\
\hline $\begin{array}{l}\text { To evaluate whether } \\
\text { introduction POC } \\
\text { diagnostics into } \\
\text { algorithms for } \\
\text { diagnosing maternal } \\
\text { patients, reduces the } \\
\text { maternal mortality } \\
\text { rate in rural } \\
\text { sub-Saharan Africa }\end{array}$ & $\begin{array}{l}\text { Evidence from a } \\
\text { systematic review } \\
\text { (highest quality of } \\
\text { evidence) indicating the } \\
\text { impact of HIV-related } \\
\text { POCT on maternal } \\
\text { outcomes of } \\
\text { HIV-infected mothers } \\
\text { will show significance } \\
\text { for POCT scale up in } \\
\text { rural and } \\
\text { resource-limited } \\
\text { maternal health clinics }\end{array}$ & $\begin{array}{l}\text { Systematic review } \\
\text { and meta-analysis }\end{array}$ & $\begin{array}{l}\text { Peer reviews } \\
\text { literature fitting } \\
\text { the inclusion } \\
\text { and exclusion } \\
\text { criteria }\end{array}$ & $\begin{array}{l}\text { analysis of MMR } \\
\text { data pre and post } \\
\text { syphilis POC } \\
\text { testing } \\
\text { interventions }\end{array}$ & $\begin{array}{l}\text { Improved } \\
\text { maternal } \\
\text { outcomes: } \\
\text { maternal } \\
\text { mortality; } \\
\text { prevention of } \\
\text { mother to child } \\
\text { transmission of } \\
\text { HIV and }\end{array}$ & Meta-analysis & $\begin{array}{l}\text { Studies reporting a } \\
\text { significant improvement } \\
\text { of maternal outcomes }\end{array}$ \\
\hline
\end{tabular}




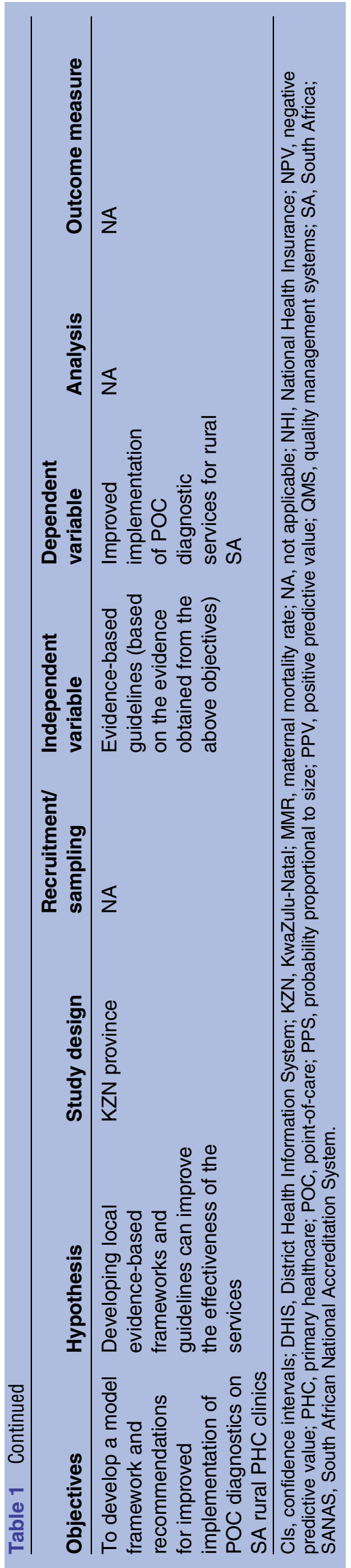

Data sources: Survey (survey tool has been provided as online supplementary material file). The cross sectional survey study protocol was developed a priori and was registered in the Clinical Trial.gov website. ClinicalTrials. gov Identifier: NCT02692274, available at: https:// clinicaltrials.gov/ct2/show/NCT02692274.

Sampling: We will conduct a stratified random sampling of PHC clinics to ensure generalisability (external validity). PHC clinic healthcare professionals responsible for the POC diagnostic services in the clinic will be requested to participate in the survey. A sample size of 100 primary units has been demonstrated to be an appropriate sample size for this type of facility-based survey. ${ }^{26}$ The most recent (2014) data on PHC headcount, professional nurse clinic workdays, annual nurse's estimate and average headcount per week was requested from the South African DHIS in order to assign sample strata. Four strata were created based on the above sets. A total of 25 facilities were sampled within each of these strata using probability proportional to size (PPS). Proportionate stratification was implemented to ensure that the sample size of each stratum is proportionate to the population size of the stratum among all $11 \mathrm{KZN}$ districts. The sample size of each stratum is proportionate to the population size of the stratum. Strata sample sizes were determined by the following equation:

$$
\mathrm{n}_{\mathrm{h}}=\left(\mathrm{N}_{\mathrm{h}} / \mathrm{N}\right) \times \mathrm{n}
$$

where $\mathrm{n}_{\mathrm{h}}$ is the sample size for stratum $\mathrm{h}, \mathrm{N}_{\mathrm{h}}$ the population size for stratum $\mathrm{h}, \mathrm{N}$ the total population size and $\mathrm{n}$ is the total sample size. Table 2 shows the sampling frame per district.

Objective 2: To investigate the deficiencies and their causes for POC diagnostics in rural PHC clinics in SA.

Data sources: In-depth interviews.

Sampling: Clinics with low POC diagnostic availability and usage based on the overall average level of availability and usage of POC diagnostics from the sampled clinics. Variables: The interviews will be aimed at gaining rich data on patients-centred and staff-centred advantages, barriers, challenges of current POC diagnostic services and future service needs.

Objective 3: To investigate the quality management systems emplaced to ensure reliability of the HIV-related POC diagnostics for maternal health in their current setting.

Data sources: Audit and validation test.

Sampling: To determine the reliability of POC diagnostic services in clinics with high availability, accessibility and usability of POC diagnostics, the quality management systems implemented in the clinics will be assessed against relevant quality indicators as prescribed by the most recent WHO guidelines for POC diagnostics in resource-limited settings, through an audit. ${ }^{27}$ The audit will include evaluation of the performance, operational characteristics of the test and linkage to healthcare. To determine reliability of the results produced by PHC 


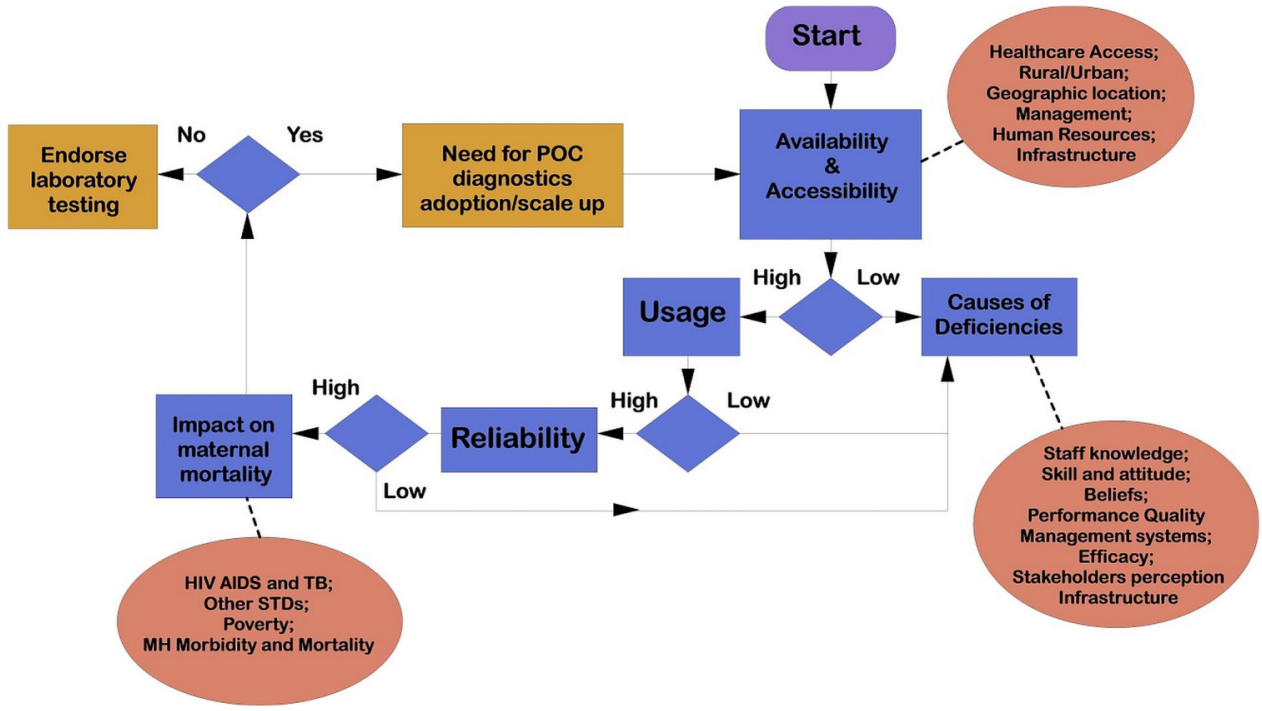

Figure 1 A theoretical framework underpinning this study, programme evaluation theory adapted to the local context. POC, point-of-care; STDs, sexually transmitted diseases; TB, tuberculosis.

clinics WHO standards, a POC diagnostic validation test will be carried out. Full blood samples will be requested from consenting women who will be attending the clinic and receiving an HIV POC diagnostic test for laboratory testing. A validation test will be conducted against the gold standard test for HIV, the ELISA test. The sample size at the required absolute precision level for sensitivity and specificity will be dependent on the survey, vertical audit results and clinic size. It will be calculated by Buderer's formula ${ }^{16}$ which is demonstrated below:

Sample size (n) based on sensitivity

$$
=\frac{\mathrm{Z}_{1-\alpha / 2}^{2} \times \mathrm{S}_{\mathrm{N}} \times\left(1-\mathrm{S}_{\mathrm{N}}\right)}{\mathrm{L}^{2} \times \text { Prevalence }}
$$

and

Sample size (n)based on the specificity

$$
=\frac{\mathrm{Z}_{1-\alpha / 2}^{2} \times \mathrm{S}_{\mathrm{p}} \times\left(1-\mathrm{S}_{\mathrm{p}}\right)}{\mathrm{L}^{2} \times \text { Prevalence }}
$$

Here, $n$ is the required sample size, $S_{N}$ the anticipated sensitivity, $S_{p}$ the anticipated specificity, $\alpha$ the size of the critical region (1- $\alpha$ is the confidence level), $Z_{1-\alpha / 2}$ the standard normal deviate corresponding to the specified size of the critical region $(\alpha)$ and $L$ is the absolute precision desired on either side (half-width of the CI) of sensitivity or specificity.

Owing to lack of laboratory infrastructure in rural and resource-limited KZN and to ensure reliability of the POC performance validation test, only PHC clinics that are within $60 \mathrm{~km}$ to the testing laboratory will be included in the POC test evaluation. It is anticipated that sensitivity (or specificity) of a given POC test is $80 \%$ for detecting a given outcome against the laboratory gold standard, assuming an absolute precision of $\pm 10 \%$ and the prevalence of outcome in the study population is $27 \%{ }^{28}$ and based on the average patient headcount per week, then it will be necessary to sample and test 207 study subjects using both the POCT and the laboratory gold standard.

Objective 4: To determine the impact of HIV-related POC diagnostics on maternal mortality using an interrupted time series study.

Data sources: South African DHIS.

Sampling: Retrospective data on rural KZN maternal mortality rate from all KZN districts. The time of POC test implementation in KZN rural clinics will be obtained from the Department of Health archives.

Variables: The following is an explanation of the method of Wagner et $a l,{ }^{29}$ applied to our practical analysis. Time series of maternal mortality rate will be assessed using segmented negative binomial regression analysis, which is a method of estimating

\begin{tabular}{llc}
$\begin{array}{lll}\text { Table 2 } \\
\text { District } \\
\text { code }\end{array}$ & Project sampling frame & \\
\hline B1 & District name & $\begin{array}{c}\text { Sample } \\
\text { number }\end{array}$ \\
B2 & Amajuba District Municipality & 6 \\
& eThekwini Metropolitan & 7 \\
B3 & Municipality & \\
B4 & iLembe District Municipality & 7 \\
B5 & Uarry Gwala District Municipality & 8 \\
B6 & uMgungundlovu District & 14 \\
& Municipality & 4 \\
B7 & uMkhanyakude District & 22 \\
& Municipality & \\
B8 & uMzinyathi District Municipality & 5 \\
B9 & uThukela District Municipality & 6 \\
B10 & uThungulu District Municipality & 18 \\
B11 & Zululand District Municipality & 3 \\
\hline
\end{tabular}


changes in levels and trends in an outcome associated with an intervention (POC diagnostics). The time series regression equation for this model is as follows:

$$
\begin{aligned}
\hat{\mathrm{Y}}_{\mathrm{t}}= & \beta_{0}+\beta_{1} \times \text { time }+\beta_{2} \times \text { intervention }+\beta_{3} \\
& \times \text { time_after_intervention }+\mathrm{e}_{\mathrm{t}}
\end{aligned}
$$

$\hat{Y}_{t}$ is the outcome (mean number of deaths per quarter), time indicates the number of quarters) from the start of the series, intervention is the dummy variable taking the values 0 in the preintervention segment and 1 in the postintervention segment, time_after_intervention is 0 in the preintervention segment and counts the quarters in the postintervention segment at time $t$. The coefficient $\beta_{0}$ estimates the base level of the outcome (number of deaths) at the beginning of the series, $\beta_{1}$ estimates the base trend, that is, the change in outcome per quarter in the preintervention segment, $\beta_{2}$ estimates the change in level of deaths on the postintervention segment, $\beta_{3}$ estimates the change in trend in deaths in the postintervention segment, $\mathrm{e}_{\mathrm{t}}$ estimates the error.

This model will be used to estimate the impact of HIV-related and MH-related POC diagnostics on maternal mortality in rural KZN.

Objective 5: To evaluate whether the introduction of POC diagnostics into algorithms for diagnosing maternal patients improves maternal health for HIV-infected women using a systematic review.

The systematic review protocol was developed a priori and was registered in the PROSPERO international prospective register of systematic reviews and in publication. ${ }^{30}$ PROSPERO record: CRD42014015439, available at: http://www.crd.york.ac.uk/PROSPERO/display_record. asp?ID=CRD42014015439\#.VSfoV-_GPug.

The systematic review will follow recommendations described in the Preferred Reporting Items for Systematic Reviews and Meta-Analyses (PRISMA) Statement ${ }^{31}$ and the Cochrane Handbook for Intervention Reviews. ${ }^{32}$ The findings of the systematic review will be disseminated through publication in a peer-reviewed journal and will be formatted according to the specific journal publication guidelines.

Data source: The studies will be selected by evaluation of the inclusion and exclusion criteria. This will be carried out in duplicate and independently by two authors with agreement assessed using $\kappa$-statistics.

Objective 6: To develop a model framework and recommendations for improved implementation of POC diagnostics on SA rural PHCs.

Guided by the information gathered from the above objectives, we will propose a model framework for improved implementation of POC diagnostics in rural SA PHCs.
Analyses

\section{Qualitative data analysis}

Interviews will be conducted with consenting participants in English. Field notes from observations will be written down about each observation session. The observations will be used to contextualise the interview findings and confirm the validity of interpretations.

We will perform a verbatim transcription of all interviews and check transcripts with study participants to seek points of clarification in relation to issues arising from interviews. We will also perform an audit trial for assessing the entire research process. Thematic content analyses will be performed to identify the patterns of POC diagnostic key utility areas and deficiencies from respondent's interviews, using NVIVO software. First, participants' responses will be coded into categories which were then grouped into themes. The codes will be grouped into similar concepts that reflect the context about local factors that determine healthcare workers and patients' engagement with POC diagnostics. Finally, the identified themes will be validated by the study supervisor. Anticipated themes include: management, human resources, infrastructure, staff knowledge, skill, attitude, believes, relevant key stakeholders' perceptions on the quality of POC diagnostics and relevant key stakeholders' perception on POC diagnostics scale-up.

\section{Quantitative analysis}

Quantitative data will be entered into a project-specific Microsoft Access database and extracted manually onto a categorised table. Data will be grouped into two levels: facility level and individual level. Facility-level data will include data from clinic audits and PHC clinic nurses. Inferential statistics will be used to determine significant differences in the availability of POC diagnostics from the sampled clinics. Standard Student's t-test and analysis of variance (ANOVA) will be used to compare means across groups while the Pearson $\chi^{2}$ test will be used for contingency tables. Factors such as distance to the nearest emergency hospital and clinic size in terms of patient volumes and staff numbers, frequency of use for the diagnostics and level of need for the diagnostics (list of POCT requested by the clinic staff during survey) will be taken into account. The reliability and accuracy of the POCT test results versus the laboratory gold standard will be estimated along with 95\% CIs. Table 1 show variables and analysis for the data obtained from the audit. Systematic review analysis will follow the relevant PRISMA guidelines as stipulated in the published protocol. ${ }^{30}$

All quantitative data will be processed and analysed using Stata V.13.0 (StataCorp. 2013. Stata Statistical Software: Release 13. College Station, Texas, USA: StataCorp L). Descriptive statistics that include frequency distribution, percentages and percentiles, means and SDs and cross-tabulations will be used to describe the characteristics of POC diagnostic service in rural KZN. A 95\% CI will be constructed around point estimates given the sampling design. 
Table 3 Study timeline

\begin{tabular}{|c|c|c|c|c|}
\hline Objectives & Data collection & Data entry and cleaning & Data analysis & Reporting \\
\hline Objective 1 & April to August 2015 & $\begin{array}{l}\text { September } 2015 \text { to March } \\
2016\end{array}$ & March 2016 to April 2016 & May 2016 \\
\hline Objective 2 & October to December 2015 & January 2016 to March 2016 & April 2016 & July 2016 \\
\hline Objective 3 & $\begin{array}{l}\text { November to } \\
\text { December } 2015\end{array}$ & $\begin{array}{l}\text { December } 2015 \text { to } \\
\text { January } 2016\end{array}$ & February to March 2016 & May 2016 \\
\hline Objective 4 & April 2015 to April 2016 & May to June 2016 & July 2016 & $\begin{array}{l}\text { September } \\
2016\end{array}$ \\
\hline Objective 5 & October 2015 & November 2015 & $\begin{array}{l}\text { December } 2015 \text { to February } \\
2016\end{array}$ & March 2016 \\
\hline Objective 6 & May 2016 & June 2016 & July 2016 & October 2016 \\
\hline
\end{tabular}

\section{Limitations}

We will address any missing data using appropriate statistical methods. ${ }^{33}$ Data can be missed for many reasons, such as on occasions when a participant did not show up to participate in a study; or one group had more participants than another; or a device did not record the data correctly. The nature of missing data will determine the statistical analysis methods to be used.

We will undertake a careful and prolonged planning of the study to reduce or eliminate the potential sources of bias including sampling bias, recall bias and reporting bias. Recall bias can be introduced into the qualitative data collection stage of investigation, presenting a major threat to the internal validity and credibility of the study. To overcome this limitation in this study, participants will be provided with enough time before answering the question, to reflect and think through a sequence of events in their professional history. The risk of bias for (eg, internal validity) the studies included in a systematic review will be evaluated using the Cochrane Risk of Bias Tool. $^{32}$

\section{ETHICS AND DISSEMINATION}

\section{Ethical principles and patient informed consent}

The study is being conducted in accordance with the Helsinki Declaration. Permission letters were obtained from all study site managers: KZN health district managers and KZN National Health Laboratory manager. Written consent authorisation will be obtained from all study participants prior to any study-related procedures being performed. Participants will be given a copy of the consent form for their record. The consent process will be documented. Participation will be voluntary and each participant will be able to drop out at any time for any reason. All discordant HIV test results will be reported to the clinic; relevant clinic staff will recall the patients involved for second sample collection and retest by the laboratory.

\section{Legal principles}

All personal data will be eliminated. All electronic data of the complete, coded documents will be saved on a protected server which can only be accessed by the members of the internal study team. The paper for the document will be stored in archives closed for external persons. Data will be kept anonymised during the study and will be kept strictly confidential in storage for 2-year after completion of the study. No identifying data will be published.

\section{Dissemination of study findings}

With this study, our aim is to influence rural PHC policy by translating research evidence to relevant stakeholders. Knowledge translation would be a key aspect of the study, where we intend to disseminate findings to contribute evidence to inform policymakers regarding guidelines for the adoption of new POC diagnostic devices and for possible scaling-up the use of POC diagnostic services, for improvement of HIV and maternal healthcare in rural resource-limited settings.

\section{Study timeline}

Table 3 depicts the study timeline for each of the study objectives.

\section{Author affiliations}

${ }^{1}$ Discipline of Public Health Medicine, School of Nursing and Public Health, University of KwaZulu-Natal, Durban, South Africa

${ }^{2}$ Department of Global Health, International Clincial Research Center, University of Washington, Seattle, Washington, USA

${ }^{3}$ Department of Medicine, Division of Infectious Diseases, University of Washington, Seattle, Washington, USA

${ }^{4}$ Department of Surgery, Massachusetts General Hospital, Harvard Medical School, Boston, Massachusetts, USA

Acknowledgements The authors acknowledge Rowan Mark Thompson (RMT) for his assistance with technical graphics. Open access publication of this article has been made possible through support from the Victor Daitz Information Gateway, an initiative of the Victor Daitz Foundation and the University of KwaZulu-Natal.

Contributors TPM-T, BS and PKD conceptualised the design of the study. TPM-T produced the first draft of the manuscript. BS and PKD commented on this draft and contributed to the final version. All the authors read and approved the final manuscript.

Funding University of KwaZulu-Natal (grant: College of Health Sciences Research Scholarship); South African Centre of Excellence for Epidemiology and Modelling Analysis (grant: PhD scholarhip); African Population and 
Health Research Centre (grant: 2015 African Doctorate Dissertation Fellowship).

Competing interests None declared.

Ethics approval The protocol was approved by the University of KwaZulu-Natal, Biomedical Research Ethics Committee (reference number: BE484/14) and the KwaZulu-Natal Department of Health Ethics Committee (reference number: HRKM 40/15).

Provenance and peer review Not commissioned; externally peer reviewed.

Open Access This is an Open Access article distributed in accordance with the Creative Commons Attribution Non Commercial (CC BY-NC 4.0) license, which permits others to distribute, remix, adapt, build upon this work noncommercially, and license their derivative works on different terms, provided the original work is properly cited and the use is non-commercial. See: http:// creativecommons.org/licenses/by-nc/4.0/

\section{REFERENCES}

1. Cullinan K. South Africa far from targets to reduce maternal, infant mortality. 30 June 2014. http://wwwhealth-eorgza/2013/10/29/ south-africa-far-targets-reduce-maternal-infant-mortality/

2. The National Strategic Plan (NSP) 2012 - 2016 in a nutshell. http:// sanacorgza/2013/07/01/the-national-strategic-plan-nsp-2012-2016in-anutshell/ (accessed 18 Jun 2015).

3. Mclntyre D, Gilson L, Wadee $\mathrm{H}$, et al. Commercialisation and extreme inequality in health: the policy challenges in South Africa. $J$ Int Dev 2006;18:435-46.

4. Woolman S, Sprague C, Black V. Why state policies that undermine HIV lay counsellors constitute retrogressive measures that violate the right of access to health care for pregnant women and infants. $S$ Afr J Hum Rights 2009;25:102-25.

5. Dhai A. A health system that violates patients' rights to access health care. S Afr J Bioeth Law 2012;5:2-3.

6. Dinnes J, Deeks J, Kunst $\mathrm{H}$, et al. A systematic review of rapid diagnostic tests for the detection of tuberculosis infection. Health Technol Assess 2007;11:1-196.

7. Shephard MDS, Mazzachi BC, Shephard AK, et al. The impact of point of care testing on diabetes services along Victoria's Mallee Track: results of a community-based diabetes risk assessment and management program. Rural Remote Health 2005;5:371.

8. Pai NP, Vadnais C, Denkinger C, et al. Point-of-care testing for infectious diseases: diversity, complexity, and barriers in low- and middle-income countries. PLoS Med 2012;9:e1001306.

9. Mabey D, Peeling RW, Ustianowski A, et al. Diagnostics for the developing world. Nat Rev Microbiol 2004;2:231-40.

10. The World Market for Point of Care (POC) Diagnostics http://wwwkalora mainformationcom/Point-Care-POC-9030928/ (accessed 18 Jun 2016).

11. Keeler E, Perkins MD, Small $P$, et al. Reducing the global burden of tuberculosis: the contribution of improved diagnostics. Nature 2006;444:49-57.
12. Scott L. A laboratorian's experience of implementing multiple point-ofcare testing in HIV antiretroviral treatment clinics in South Africa. S Afr Med J 2013;103:883-4.

13. Nabyonga J, Orem J. From knowledge to policy: lessons from Africa Sci Transl Med 2014:6:240ed13.

14. Drain PK, Hyle EP, Noubary F, et al. Diagnostic point-of-care tests in resource-limited settings. Lancet Infect Dis 2014;14:239-49.

15. Yager P, Domingo GJ, Gerdes J. Point-of-care diagnostics for global health. Annu Rev Biomed Eng 2008;10:107-44.

16. Buderer NM. Statistical methodology: I. Incorporating the prevalence of disease into the sample size calculation for sensitivity and specificity. Acad Emerg Med 1996;3:895-900.

17. Cojocaru S. Clarifying the theory-based evaluation. Rev Cercet Interventie Sociala 2009;26:76-86.

18. Mercer SH, Idler AM, Bartfai JM. Theory-driven evaluation in school psychology intervention research: 2007-2012. Sch Psychol Rev 2014;43:119-31.

19. Haji F, Morin M-P, Parker K. Rethinking programme evaluation in health professions education: beyond 'did it work?' Med Educ 2013;47:342-51.

20. Lynch BK. Language assessment and programme evaluation. Edinburgh University Press, 2003.

21. Bickman L. The functions of program theory. New Directions for Program Evaluation 1987;1987:5-18.

22. Ryan AB. Post-positivist approaches to research [Researching and writing your thesis: a guide for postgraduate students]. 2006:12-26.

23. Denzin NK, Lincoln YS. The SAGE handbook of qualitative research: Sage, 2011.

24. Adami MF, Kiger A. The use of triangulation for completeness purposes. Nurse Res 2005;12:19-29.

25. Africa SS. Mid-year population estimates. Statistics South Africa Pretoria, 2013.

26. Valliant R, Dever JA, Kreuter F. Practical tools for designing and weighting survey samples. Springer, 2013.

27. Wu G, Zaman MH. Low-cost tools for diagnosing and monitoring HIV infection in low-resource settings. Bull World Health Organ 2012;90:914-20.

28. Burd EM. Validation of laboratory-developed molecular assays for infectious diseases. Clin Microbiol Rev 2010;23:550-76.

29. Wagner AK, Soumerai SB, Zhang F, et al. Segmented regression analysis of interrupted time series studies in medication use research. J Clin Pharm Ther 2002;27:299-309.

30. Mashamba-Thompson TP, Sartorius B, Thabane L, et al. Impact of point-of-care diagnostics on maternal outcomes in HIV-infected women: systematic review and meta-analysis protocol. BMJ Open 2016;6:e008002.

31. Moher D, Liberati A, Tetzlaff J, et al. Preferred Reporting Items for Systematic Reviews and Meta-Analyses: the PRISMA Statement. Ann Intern Med 2009;151:264-9.

32. Higgins JP, Green S. Cochrane Handbook for Systematic Reviews of Interventions. Wiley Online Library, 2008.

33. Howell DC. The analysis of missing data. In: Outhwaite W, Turner S Handbook of Social Science Methodology. London: Sage, 2007. 